\title{
SIGNIFICADOS E VIVÊNCIAS EM TORNO DA \\ ADIÇÃO DE SUBSTÂNCIAS: TEORIA FUNDAMENTADA NOS DADOS
}

\section{MEANINGS AND EXPERIENCES ON SUBSTANCE ADDICTION: GROUNDED THEORY}

\section{SIGNIFICADOS Y VIVENCIAS CON RESPECTO A LA ADICCIÓN A SUBSTANCIAS: TEORÍA FUNDAMENTADA}

\author{
Mariana Morais ${ }^{1}$ \\ Rui Paixão ${ }^{2}$
}

Como citar este artigo: Morais M, Paixão R. Significados e vivências em torno da adição de substâncias: teoria fundamentada nos dados. Rev baiana enferm. 2020;34:35002.

\begin{abstract}
Objetivo: analisar a trajetória de sujeitos adictos, procurando compreender de que forma percebem o seu percurso no mundo das drogas, tomando por referência central as perceções, representações e significados que atribuem à droga e ao sentido da sua própria vida, antes, durante e após as vivências de adição. Método: pesquisa qualitativa, com base na Teoria Fundamentada nos Dados. Foram entrevistados oito sujeitos internados numa Comunidade Terapêutica de toxicodependência em Portugal, entre os meses de setembro e dezembro de 2016. Resultados: obtiveram-se três grupos de categorias principais: "Evolução do padrão de consumo", "Trajetória comportamental durante os consumos", e "Transformação identitária"; uma categoria intermédia "Alteração dos valores morais e sociais; e a categoria nuclear "Identidade adicta". Conclusão: os sujeitos compreendem a trajetória adicta como um conjunto de mudanças progressivas na sua identidade, fortemente associadas a alterações dos valores morais e sociais. Referem-se à droga como a sua autodestruição, expressando culpa e arrependimento.
\end{abstract}

Descritores: Adição. Droga. Trajetória de Vida. Identidade. Teoria Fundamentada nos Dados.

Objective: to analyse the trajectory of individuals suffering from addiction, seeking to understand how they perceive their path in the world of drugs, with a core focus on the perceptions, representations and meanings they assign to drugs and their life path before, during and after their experiences with addiction. Method: qualitative research based on Grounded Theory. Eight subjects admitted to Community Therapy for substance addiction in Portugal were interviewed from September to December 2016. Results obtained: three main category groups: "Pattern consumption evolution", "Behavioural trajectory while consuming", and "Identity Transformations"; an intermediate category "Alteration of moral and social values"; and a core category "Addictive Identity". Conclusion: the subjects understand the addict's trajectory as being a set of progressive changes in one's identity, strongly associated with alterations in moral and social values. They refer to drugs as their self-destruction, expressing guilt and regret.

Descriptors: Addiction. Drugs. Life Path. Identity. Grounded Theory.

Objetivo: analizar la trayectoria de toxicómanos, buscando comprender como perciben su camino en el mundo de las drogas, teniendo como referencia central las percepciones, representaciones, y los significados que atribuyen a las drogas y al sentido de sus propias vidas, antes, durante, y después de sus experiencias con la adicción. Método:

Psicóloga. Mestre em Psicologia Clínica e da Saúde. Pesquisadora independente. Coimbra, Portugal. mariana-c11@hotmail.com. https://orcid.org/0000-0002-4387-043।.

Psicólogo. Doutor em Psicologia Clínica. Professor Associado da Universidade de Coimbra. Coimbra, Portugal. https://orcid.org/0000-0002-0369-2829. 
pesquisa cualitativa, basada en la Teoría Fundamentada. Se entrevistó ocho sujetos hospitalizados en una Comunidad Terapéutica de dependencia de tóxicos en Portugal, de septiembre a diciembre de 2016. Resultados: se encontró tres grupos de categorías principales: "Evolución de la estructura de consumo", "Trayectoria comportamental durante el consumo", y "Trasformación identitaria"; una categoría intermediaria "Alteración de los valores morales y sociales"; y la categoría nuclear "Identidad adicta". Conclusión: los sujetos comprenden la trayectoria adicta como un grupo de cambios progresivos en sus identidades, fuertemente asociado a alteraciones en sus valores morales y sociales. Se refieren a la droga como su autodestrucción, expresando culpa y arrepentimiento.

Descriptores: Adicción. Trayectoria de Vida. Identidad. Muestreo Teórico.

\section{Introdução}

O consumo de drogas, é um fenómeno antigo e persistente ao longo da história da humanidade $^{(1)}$, sendo diversas as razões que podem motivar alguém a consumir, desde a procura do prazer, o alívio do sofrimento, entre outras. Entende-se "droga" como toda substância, natural ou sintética, capaz de modificar as funções do organismo, e "dependência de drogas", como um conjunto de fenómenos comportamentais, cognitivos e fisiológicos que se desenvolvem depois do uso repetido de uma substância, incluindo um forte desejo de tomar a droga, dificuldades em controlar o seu uso (apesar das consequências nefastas), maior prioridade dada ao consumo do que a outras atividades e responsabilidades, tolerância aumentada, e por vezes, um estado de privação física ${ }^{(2)}$. De acordo com o grau de dependência que uma dada substância é capaz de provocar, pode-se falar de drogas leves (baixo grau de dependência, como a cannabis) e drogas pesadas (elevado grau de dependência, como a heroína e cocaína).

O estudo das adições é, atualmente, uma temática de interesse científico e social, já que o uso de drogas é um problema de saúde pública cada vez mais frequente nos nossos dias, acarretando diversos prejuízos sociais, tais como: o aumento da violência e criminalidade; problemas de saúde; problemas familiares; aumento da transmissão de doenças infeciosas por meio de relação sexual desprotegida; e partilha de agulhas ${ }^{(3)}$.

A adição é um fenómeno complexo que pode ser analisado segundo diversos pontos de vista: médico, jurídico-legal, social, psicológico. Nesta investigação, partiu-se da premissa de que mais do que a substância em si, são as características do sujeito, suas motivações, e os significados que atribui à droga, que determinam o consumo de determinada substância; consequentemente, o objeto deste estudo são as narrativas dos sujeitos dependentes.

Pretende-se explorar as seguintes questões de investigação: O que leva alguém a consumir? Como se desenvolve uma trajetória de vivências adictas? Que alterações ocorrem na vida do sujeito decorrentes dessas vivências? Quais as perspetivas que o sujeito constrói em torno do seu percurso no mundo das adições e que significados atribui à droga?

O objetivo desta investigação é analisar a trajetória de sujeitos adictos, procurando compreender de que forma percebem o seu percurso no mundo das drogas, tomando por referência central as perceções, representações e significados que atribuem à droga e ao sentido da sua própria vida, antes, durante e após as vivências de adição.

\section{Método}

Tendo em vista que o ser humano é complexo e orienta a sua ação com base em significados próprios, recorreu-se à Teoria Fundamentada nos Dados (TFD), um método de investigação qualitativa. Trata-se de um método dinâmico que permite a interação do investigador com o contexto de investigação e no qual as perspectivas pessoais dos entrevistados são transformadas em produtos de pesquisa, valorizando-se a singularidade da sua experiência ${ }^{(4-5)}$.

A TFD foi desenvolvida por Glaser e Strauss em 1967, com o propósito de construir teorias com base em dados, mediante um método de comparação constante $^{(6)}$. Nessa metodologia, a amostra deve ser representativa das variações e tipicidades do fenómeno. Dessa forma, os participantes são intencionalmente escolhidos, por apresentarem um conhecimento profundo sobre o fenómeno ${ }^{(7)}$. O critério de inclusão para 
a constituição da amostra foi: pessoas adultas (independentemente do gênero), com trajetória de dependência de substâncias pesadas (heroína e/ou cocaína), internadas numa instituição para tratamento das respectivas adições. Apresenta-se, em seguida, breve descrição dos sujeitos entrevistados, tendo sido utilizados nomes fictícios, para garantia do anonimato: Ana (48 anos), 12을 ano de escolaridade, solteira e sem filhos, desempregada, primeiro consumo de haxixe aos 16 anos, heroína aos 18/19 anos, cocaína aos 18/19 anos; Cátia (43 anos), 12을 ano de escolaridade, solteira e sem filhos, desempregada, primeiro consumo de haxixe aos 16 anos, heroína aos 16 anos, cocaína aos 18 anos; Clara (27 anos), 8o ano de escolaridade, solteira e sem filhos, desempregada, primeiro consumo de haxixe aos 13/14 anos, heroína aos 17 anos, cocaína aos 17 anos; João (38 anos), 9ำ ano de escolaridade, divorciado, tem uma filha de 13 anos, desempregado, primeiro consumo de haxixe aos 19 anos, heroína aos 24 anos, cocaína aos 24 anos; José ( 43 anos), 10ำ ano de escolaridade, solteiro, tem um filho de 5 anos, desempregado, primeiro consumo de haxixe aos 14/15 anos, heroína aos 16/17 anos, cocaína aos 21 anos; Nuno (39 anos), $9^{\circ}$ ano de escolaridade, divorciado, tem um filho de 17 anos, desempregado, primeiro consumo de haxixe aos 13 anos, heroína aos 14 anos, cocaína aos 19 anos; Rui (41 anos), 11ำ ano de escolaridade, divorciado, tem um filho de 6 anos, desempregado, primeiro consumo de haxixe aos 13 anos, heroína aos 17 anos, cocaína aos 20 anos; Sandra (32 anos), 9o ano de escolaridade, divorciada, tem um filho de 8 anos e uma filha de 14 anos, desempregada, primeiro consumo de haxixe aos 16 anos, heroína aos 27 anos, cocaína aos 27 anos.

Para a coleta dos dados foi realizada uma entrevista em profundidade, semiestruturada, onde constavam questões orientadoras, relativamente a:

a) entrada do sujeito no mundo da droga: "Recorda-se da sua primeira experiência com drogas?, "O que consumiu?", "Onde estava?", Com quem consumiu?";

b) evolução do padrão de consumo: "O que o levou a repetir a experiência?", "Quando se dá a introdução de substâncias pesadas (heroína/cocaína)?", "Com que frequência e em que contexto, ocorriam os consumos?", "Com quem consumia?";

c) questões de cariz subjetivo relativo às diversas dimensões de vida do sujeito: familiar ("Com quem vivia?", "Considera que a droga teve impacto na sua relação com a família?”, "De que modo?"); social ("Considera que a caminhada no mundo da droga interferiu na relação com os seus amigos/pessoas significativas?", "De que forma?"); profissional ("Desempenhava alguma ocupação profissional? Qual?", "Considera que a droga teve impacto na sua vida profissional? De que modo?") e por fim intrapessoal ("Recorda-se de si antes da droga?", "Considera que era uma pessoa diferente?", "Sente que a droga o mudou?", "De que forma?").

As entrevistas foram realizadas presencial e individualmente na instituição de tratamento, tendo sido gravadas em registro áudio. Posteriormente, foram transcritas para um documento Word para serem analisadas em profundidade, pois na TFD, para o trabalho ser considerado válido e fidedigno, os casos precisam estar bem descritos, a análise transparecer coerência e consistência ${ }^{(8)}$, e as categorias e subcategorias apresentarem densidade conceitual, isto é, encontrarem-se fortemente interligadas ${ }^{(6)}$. A coleta de dados ocorreu durante dois meses, e a amostra foi fechada após terem sido entrevistados oito sujeitos (quatro homens e quatro mulheres), quando se atingiu a saturação teórica, isto é, os casos analisados deixaram de acrescentar informação nova relevante para a análise ${ }^{(9)}$. Nas entrevistas visou-se dar a máxima liberdade ao sujeito, de modo que este pudesse partilhar livremente a sua experiência.

Posteriormente, seguiu-se o processo de codificação (aberta, axial e seletiva) que consiste em extrair os conceitos dos dados, e estudar as suas propriedades e dimensões ${ }^{(6)}$. Na codificação aberta, os dados foram decompostos em ideias e conceitos, que foram posteriormente agrupados em categorias. Na codificação axial, essas categorias foram agrupadas em categorias de nível hierárquico superior e mais abstrato, de 
4

Significados e vivências em torno da adição de substâncias: teoria fundamentada nos dados

acordo com as relações que se estabeleceram entre elas ${ }^{(10)}$. Esse processo de codificação conduziu à obtenção de uma categoria nuclear (core category), "identidade adicta", que representa o fenómeno central desta investigação. Na codificação seletiva, para além de ter sido selecionada a categoria principal, procedeu-se a integração das restantes categorias em torno desta. Ao longo da análise, recorreu-se à escrita de memorandos, que constituem um recurso fundamental para a fase de escrita da teoria ${ }^{(11)}$.

Para que a coleta de dados fosse possível, foi realizado um pedido de autorização à instituição de tratamento, e posteriormente aos utentes, tendo estes decidido participar de livre vontade. Após terem sido informados acerca dos objetivos e métodos da investigação, os utentes assinaram um consentimento no qual constava a informação que se salvaguardava o respeito pelas questões éticas relativas ao seu anonimato. A investigação teve sempre presente o respeito pelos sujeitos, observando-se os princípios da autonomia, não maleficência, beneficência, justiça e equidade. A coleta de dados e o processo de codificação foram realizados por apenas um investigador.

\section{Resultados}

Da análise dos dados, emergiram três grupos categoriais principais: "Evolução do padrão de consumo", "Trajetória comportamental durante os consumos", e "Transformações identitárias", que se encontram intimamente relacionados e remetem para a categoria "Identidade Adicta". Esta, por sua vez, considerando as inter-relações entre as categorias e subcategorias, surgiu como fenómeno central de estudo. Além disso, foi identificada uma categoria intermédia, a "Alteração dos valores morais e socias". Na Figura 1 é apresentado o diagrama com a integração destas categorias na qual também é possível observar as subcategorias que compõem cada grupo categorial.

Figura 1 - Significados e vivências em torno da adição de substâncias

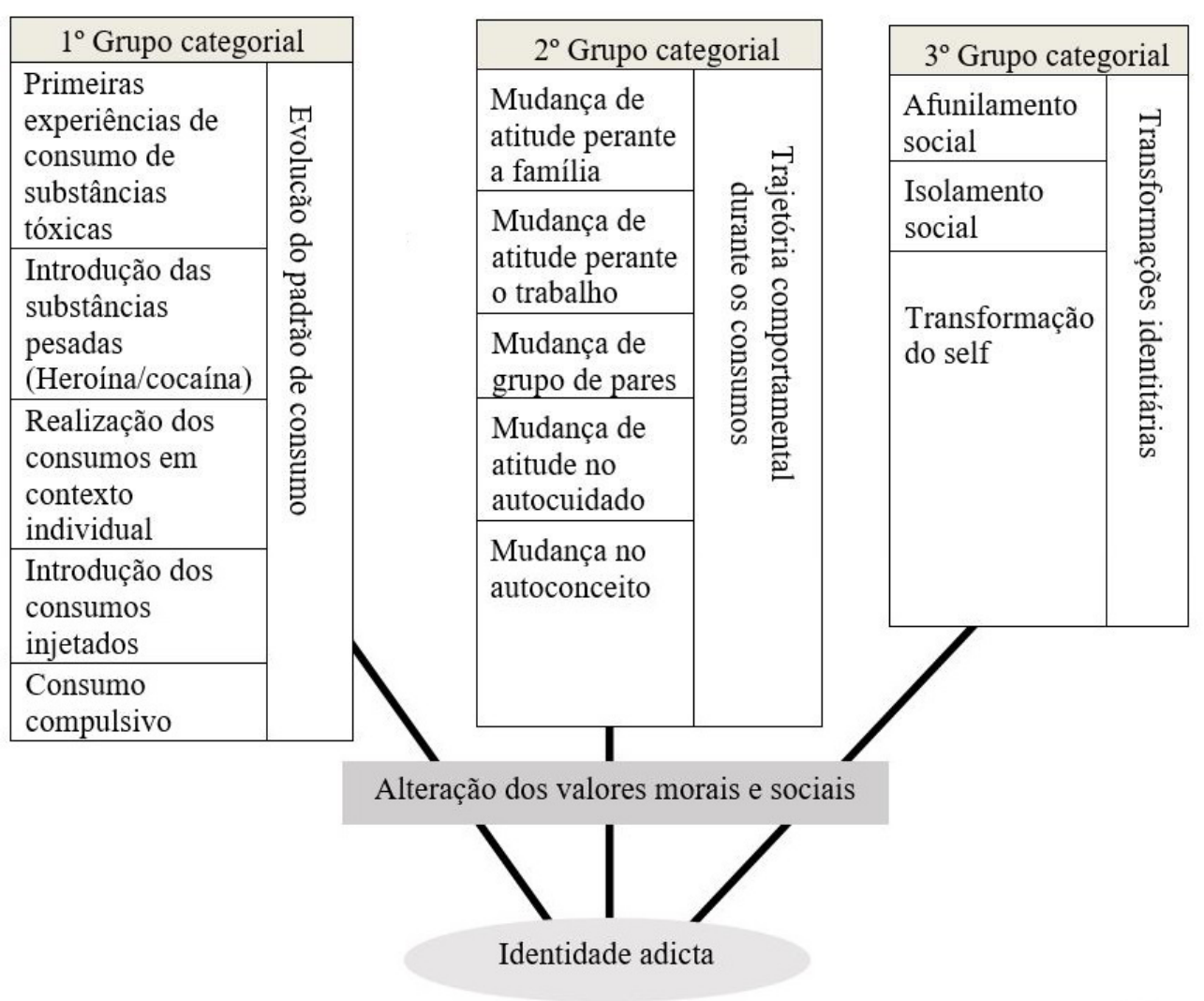

Fonte: Elaboração própria. 


\section{Identidade adicta}

Esta surge como categoria central após a compreensão de que os sujeitos sentem o percurso nas drogas como um conjunto de mudanças progressivas na sua identidade.

Eu deixei de ser o que era. (Sandra).

Muitas vezes não nos reconhecemos. (Cátia).

Como é que uma pessoa muda assim em tão pouco tempo? (Clara).

Os utentes explicaram que à medida que os consumos aumentavam, a sua atitude perante a família, emprego, relações sociais e até no autocuidado foi se modificando, tornando-se cada vez mais negligente e irresponsável. Como se, gradualmente, os seus valores fossem se alterando e esses aspectos perdessem relevância, em prol da nova prioridade que se instituía: a droga. Tendo em vista a necessidade de obter dinheiro para os consumos, vai crescendo um discurso cada vez mais baseado na mentira e na manipulação, e começam inclusivamente a surgir comportamentos desviantes como traficar, assaltar, roubar, prostituir. Assim, os dados evidenciam que as mudanças que os sujeitos relatam relativamente à sua identidade, surgem fortemente associadas a um sentimento profundo de alteração de valores, emergindo a categoria "Alteração dos valores morais e sociais".

\section{Alteração dos valores morais e sociais}

Os fragmentos a seguir expressam os sentimentos dos sujeitos:

\footnotetext{
Se quisesse consumir enganava toda gente. Desci tão baixo. Roubei a minha família [...] Até as panelas da minha mãe foram para o sucateiro [...] Alinhei em assaltos à mão armada. (João).
}

Fiz desfalques na empresa do meu pai. (Rui).

Para viver da droga tinha que me prostituir. (Sandra).

Juntei-me a uma gangue, faziamos assaltos e também traficávamos [...] Quando consumimos e estamos a ressacar, os nossos valores alteram-se. Vale tudo. (Nuno).

Uma ressaca e a vida de rua, acabamos por perder alguns valores [...] Eles alteram-se, desvanecem-se. (Cátia).

Em seguida, são explicadas as subcategorias que compõem cada grupo categorial.

\section{Evolução do padrão de consumo}

"Primeiras experiências de consumo de substâncias tóxicas": os utentes consideram ter iniciado a caminhada no mundo das drogas com os consumos de haxixe durante a adolescência. No entanto, não mostram qualquer tipo de culpa ou arrependimento, pois consideram o consumo desta substância como uma experiência "normal" entre os jovens, interpretando-a como uma experiência grupal e de finalidade lúdica.

Foi uma experiência entre amigos, na altura era normal. (José).

Foi com amigos num acampamento, representou galbofa e alegria. (Rui).

"Introdução das substâncias pesadas": os consumos de drogas pesadas (cocaína e heroína) ocorrem posteriormente, como resposta à necessidade de consumir algo mais forte, ou pela simples curiosidade.

Acabei por querer algo mais forte, então experimentei cocaína e heroína [...] Andava a procura do que é que a droga fazia. (João).

Apenas dois dos utentes relacionam esses consumos com momentos de vida particularmente difíceis, explicando que utilizaram a droga como estratégia para lidar com as emoções negativas.

Consumia grandes quantidades de tudo para desligar mesmo da vida, apagar. (Rui).

"Realização dos consumos em contexto individual": inicialmente, os consumos de heroína e/ou cocaína começam por ocorrer na companhia de alguém, podendo nesta fase comportar uma espécie de significado social. No entanto, à medida que os consumos aumentam, vai ocorrendo um progressivo isolamento, no qual a droga vai perdendo qualquer sentido social e os consumos passam a ocorrer unicamente como uma necessidade de evitar a ressaca.

Eu já não consumia socialmente. Eu já ia comprar e fumar sozinho. (José).

"Introdução dos consumos injetados": o fato da droga assumir, aos poucos, um significado de dependência é reforçado pela introdução dos consumos injetados, que ocorre como resposta à 
necessidade de um efeito maior, evidenciado o aumento da tolerância.

Comecei a perder a moca [expressão utilizada para se referir a si sob o efeito da droga] por excesso de consumos e disseram-me que se injetasse conseguia a moca mais rápido com pouco. (Ana).

"Consumo compulsivo": os sujeitos vão progressivamente perdendo o controle sobre o seu comportamento e os consumos, além de regulares, tornam-se desmedidos.

Comecou por ser uma vez por mês, depois uma vez por semana e acabou a ser todos os dias. (João).

Não conseguia controlar, é uma coisa brutal [...] 3000 euros na mão podem ir num dia [...] Não se para enquanto se tem dinbeiro. (Rui).

Seguem-se as subcategorias relativas à "Trajetória comportamental durante os consumos".

\section{Trajetória comportamental durante os consumos}

"Mudança de atitude perante a família": as rotinas de consumo tornam-se incompatíveis com a vida familiar. Os utentes começam a negligenciar as responsabilidades conjugais e parentais, acabando na maioria dos casos por abandonar a família. Revelam que deixaram de se importar com as necessidades dos seus cônjuges, filhos, pais, amigos, tornando-se totalmente autofocados. No caso dos utentes com filhos, ocorreu o total abandono das responsabilidades parentais, deixando a criança ao cuidado de outro familiar. Se a minha filha precisasse, ou a minha mãe, não queria
saber de nada, só da droga [...] Pus a minha família em
segundo lugar [...] Quando saí de casa, a minha filha
tinha três anos, praticamente cresceu sem mim. (João).

Era impossivel alguém [referindo-se à esposa] aguentar o meu estilo de vida [...] Lembro-me de pensar no meu filho e na merda toda que ia fazer, mas não conseguia parar [...] Eu saí de casa e só ia de vez em quando ver o meu filho. (Rui).

Tinha o aniversário da minha irmã, a família estava toda reunida, só que eu tinha que ir consumir. Pus a droga em primeiro lugar [...] Atualmente, é a minha irmã que toma conta do meu filho. (Sandra).

"Mudança de atitude perante o trabalho": no âmbito profissional, os utentes começam por deixar de cumprir os horários laborais e negligenciar o desempenho das suas tarefas; em alguns casos, chegaram inclusivamente a realizar consumos no local de trabalho. Consequentemente, origina-se uma situação de precariedade e instabilidade profissional, já que em qualquer novo local de trabalho, repete-se a conduta negligente e a ausência de responsabilidade profissional.

Inventamos desculpas, um dia não posso, outro chego atrasada [...] Começa-se a notar e não há hipótese de manter o trabalbo por muito tempo, começa-se a mudar muitas vezes de trabalbo. (Cátia).

O patrão dava-me uma medida, as coisas saíam com outra. (Nuno).

Trabalhei numa pastelaria e mandava canecos [utensílio usado para fumar droga] nas casas de banbo. (Clara).

Ia toda mocada [referindo-se a si sob o efeito de droga] para o emprego [...] Não estava com a cabeça no trabalho, não me conseguia concentrar. (Sandra).

"Mudança de grupo de pares": à medida que os consumos aumentam, os sujeitos vão se aproximando de pessoas igualmente ligadas à adição, com as quais estabelecem relações superficiais e instrumentais. São relações regidas unicamente pelo interesse em consumir a droga e totalmente vazias do ponto de vista emocional.

Os verdadeiros amigos, amigos mesmo, de infância, de trabalbo, familiares [tios, primos...] perdi tudo. (João).

Comecei a conbecer outros grupos. As pessoas com que me dava passaram a ser o mundo da droga. Eram só drogados. (Sandra).

São relações muito descartáveis. Nas relações da droga nós usamos as pessoas e as pessoas usam-nos a nós e basicamente é isto. (Cátia).

Tenho noção de que não há amigos na droga. (Clara).

Era só consumir e pouca confiança. Era com o proveito e só. Só falávamos sobre droga. (Ana).

"Mudança de atitude no autocuidado": os utentes começam a negligenciar o cuidado consigo mesmo, vai crescendo um sentimento de indiferença relativa aos cuidados básicos de higiene, alimentação e até de habitação (alguns utentes chegaram, inclusivamente, a viver como sem-abrigo).

Desleixei-me [...] Não tratava de mim. (Clara).

Na altura estava lá o Casal Ventoso, que é um grande bairro de droga em Lisboa e eu tive uma fase que morei lá, como sem-abrigo [...]. Deixei de lavar os dentes, de tomar banbo, deixei de ter uma mesa para comer. (Cátia).

Cheguei a comer dos caixotes do lixo, só para ter o dinheiro. Mesmo que fosse roubar, em vez de tirar o dinbeiro para comer, gastava tudo na droga. Nem um café 
tomava, ou um pão comprava [...] Naquela altura podia andar à chuva, ao frio, dormir ao relento [...] (João).

Deixava-me ir, não fazia a barba, dormia nos cantos. Era indiferente. (Nuno).

Estive com um companheiro, durante mais ou menos dois anos, a viver numa casa abandonada. (Sandra).

Resultantes da privação dos cuidados básicos de higiene e alimentação, os utentes referem consequências físicas graves, sobretudo problemas dentários e desnutrição extrema.

Em duas semanas perdi $11 \mathrm{~kg}$. Cheguei aos $44 \mathrm{~kg}$. (Clara).

"Mudança no autoconceito": os sujeitos revelam atualmente uma imagem negativa de si com uma elevada baixa autoestima. Sobretudo as mulheres, revelaram com mágoa um desgosto profundo na sua imagem atual, comparando-a constantemente com a que tinham anteriormente à toxicodependência.

Perdi a autoestima, na droga toda gente perde. (Nuno).

Antes da droga era muito jeitosa, bonita [...] passava na rua e assobiavam [...] Cuidava de mim, era muito vaidosa [...] Tenbo desgosto naquilo que sou neste momento. (Sandra).

Tinha o cabelo loiro muito comprido [referindo-se a si antes da dependência de substâncias] chamavam-me Barbie por eu ser loira e ter os olhos azuis. Hoje sou uma pessoa feia que não gosta de mim, não me consigo ver ao espelho. (Ana).

As várias alterações comportamentais referidas e observadas nas diversas esferas relacionais do sujeito acarretam mudanças na sua identidade, surgindo o terceiro grupo categorial.

\section{Transformações identitárias}

Este grupo é fortemente marcado pelas alterações que ocorrem no âmbito social (nomeadamente o progressivo afunilamento das relações interpessoais e isolamento) e individual (mediante as transformações do self, que se manifestam tanto no físico, como no subjetivo e psicológico). Essa transformação identitária é acompanhada de fortes sentimentos de autodestruição, culpa e arrependimento.

A droga mudou-me completamente. (Clara).

Fiquei totalmente diferente [...] O feitio da própria pessoa torna-se diferente. (Sandra).
Muda a personalidade da pessoa completamente [...] Estraguei-me toda. (Ana).

A droga foi a minha destruição total. (João).

\section{Discussão}

O conceito "identidade" assume grande importância nesta investigação. Refere-se ao sentido consciente que o sujeito tem da sua singularidade e ao esforço permanente que faz para manter a continuidade da sua experiência ${ }^{(12)}$. A construção da identidade ocorre ao longo de toda a vida, mas a adolescência é um período crucial, pois representa um tempo de moratória psicossocial, isto é, um período em que o jovem tem oportunidade de experimentar diversos papéis, descobrindo o que gosta e o que não gosta, quem é e quem não é, quais sãos os seus talentos e aptidões, quais são as suas limitações, os papéis nos quais se sente bem e aqueles que não gosta de desempenhar ${ }^{(12)}$. É um período de experimentação, em que o sentimento de identidade vai se desenvolvendo e amadurecendo. Esse aspecto é muito pertinente, pois se observa que a maioria dos sujeitos iniciou o consumo de drogas (inclusivamente as pesadas, heroína/cocaína) durante a adolescência, o que pode, dessa forma, comprometer o processo de moratória psicossocial e maturação do self.

A expressão para referir o sentimento de identidade é "eu sou eu", e consiste na capacidade do sujeito continuar a sentir-se o mesmo ao longo das sucessivas mudanças, podendo vacilar em circunstâncias em que não é capaz de tolerar as mudanças que ocorrem dentro de si ou na realidade ${ }^{(13)}$. Nos seus relatos, os sujeitos referem que, ao longo do percurso nas drogas, foram deixando de se sentirem eles próprios. Estabelecendo um paralelo com os conceitos previamente referidos, é como se o seu sentimento de identidade ("eu sou eu") tivesse "vacilado".

"Eu deixei de ser o que era". (Sandra).

Pode-se também dizer que o sentimento de identidade é uma espécie de unidade funcional, composta pelos elementos com os quais o sujeito se reconhece, afastando-se daqueles com quem 
não se identifica ${ }^{(14)}$. Mais uma vez, estabelecendo uma ponte com os relatos dos utentes, parece existir uma quebra nesse sentimento de unidade, tendo em conta a adoção de comportamentos nos quais, inicialmente, eles não se reconheciam.

Fiz coisas que jamais faria. (Clara).

$\mathrm{Na}$ sequência dessas mudanças, os sujeitos revelam atualmente uma imagem de si negativa, muito marcada pela baixa autoestima. Além disso, as mudanças não ocorrem apenas na forma como o sujeito percebe a si próprio, elas atingem uma dimensão social da identidade já que o sujeito vai progressivamente limitando as suas relações ao universo das drogas, passando a ser visto pelos outros (família, amigos próximos, sociedade) como fazendo parte desse grupo.

Comecei a juntar-me com pessoal que era bem conbecido lá naquele bairro; era só escumalha. As pessoas que me conbeciam começaram a associar-me ao grupo dos drogados. (Nuno).

Esse afunilamento, cada vez maior na subcultura da droga, leva o sujeito a afastar-se das pessoas significativas e a negligenciar qualquer responsabilidade. Verificou-se também, nos utentes com filhos, o abandono das responsabilidades parentais. Essa informação é suportada pela literatura que refere que o consumo de drogas é disfuncional e incompatível com a execução das competências básicas parentais, pois os pais consumidores de drogas alteram o seu comportamento parental, diminuindo a sensibilidade e a atenção ${ }^{(15)}$. Além disso, o consumo interfere nas suas capacidades de regulação emocional, de julgamento, e até em aspectos relativos às funções executivas e capacidades motoras ${ }^{(15)}$.

A subcultura da droga vai fechando o sujeito num mundo totalmente alienado dos valores da sociedade. Nessa nova realidade, as normas sociais vão deixando de fazer sentido, pois a conduta do sujeito passa a ser orientada unicamente pela necessidade de consumir. Se, em prol da droga, for necessário roubar, traficar, prostituir-se, o sujeito dependente o fará. O seu critério de valores passa a ser muito diferente, os valores morais e éticos sofrem flutuações, pois a motivação para consumir leva à sua transgressão ${ }^{(16)}$. Assim, as drogas surgem frequentemente associadas ao crime, relacionando-se com ele de várias maneiras ${ }^{(17)}$. No entanto, a relação entre as adições, trajetórias desviantes e o crime, não é linear, podendo observar-se diversos tipos de situações ${ }^{(18)}$. Neste estudo, as condutas desviantes surgiram no decorrer da trajetória adicta, isto é, nos utentes entrevistados, a delinquência e o crime apareceram secundariamente à dependência, como um meio para sustentar os consumos. Entretanto, edifica-se um ciclo vício-crime que acaba por se repetir e perpetuar-se, pois sem outra forma para sustentar os consumos, o sujeito adicto volta para as atividades ilegais, como tráfico, roubo e prostituição ${ }^{(19)}$.

Relativamente à personalidade do sujeito adicto, observa-se que se tratam frequentemente de organizações borderline da personalidade, marcadas pela difusão da identidade e ausência de representações estáveis de si e dos outros ${ }^{(20)}$. Tratam-se de personalidades imaturas e sem limites bem definidos. No entanto, apesar de ser possível identificar alguns traços comuns entre sujeitos adictos, até o momento não se conseguiu definir claramente um tipo específico de personalidade, verificando-se apenas grande heterogeneidade de situações sob a designação geral de dependência de drogas ${ }^{(21)}$. Além disso, verificam-se níveis de psicopatologia elevados na população adicta ${ }^{(22)}$, com predominância nas perturbações de humor, ansiedade e personalidade ${ }^{(23)}$.

De facto, a adição e a psicopatologia encontram-se frequentemente interligadas, observando-se com regularidade situações de comorbilidade e a existência de perturbações psiquiátricas em simultâneo no sujeito adicto ${ }^{(24)}$. Independentemente da especificidade da situação clínica encontrada, o elemento que a literatura aponta como transversal às diversas adições de droga é a presença de um elevado sofrimento psicológico, tal como foi observado nesta investigação. O indivíduo dependente de drogas apresenta frequentemente dificuldades na regulação das suas emoções, surgindo a droga muitas vezes como resposta a esta dificuldade e à libertação de estados emocionais negativos ${ }^{(25)}$. 
A presente investigação revelou alguns limites, nomeadamente o de não conseguir definir claramente um tipo específico de personalidade adicta, revelando apenas a complexidade dessa questão, e apontando, como elemento transversal aos vários casos analisados, a existência de um elevado sofrimento psicológico (informação consistente com a literatura existente). Também não é possível generalizar os resultados, pois se trata de um estudo qualitativo restrito apenas a uma realidade. No entanto, o estudo pode facilitar a compreensão de outras situações, em que sejam encontrados aspetos semelhantes que tornem possível aplicar uma compreensão teórica equivalente, podendo comportar desse modo uma espécie de poder preditivo ${ }^{(6)}$.

Além disso, considera-se que esta investigação representa um contributo importante para o estudo da toxicodependência, especificamente no que diz respeito ao seu tratamento, pois ao analisar esta problemática segundo o ponto de vista do próprio sujeito, propiciou a oportunidade de alcançar um conhecimento mais profundo acerca dos processos psicológicos subjacentes à adição, podendo assim direcionar a intervenção de forma mais especifica e, portanto, com maior probabilidade de eficácia. Esse aspeto é bastante relevante, tendo em conta que um dos grandes problemas no âmbito da intervenção nas adições é, precisamente, a presença de recaídas frequentes.

Observou-se também que à medida que a droga vai assumindo o lugar central na vida do sujeito, este vai se alienando da sociedade, e a sua estrutura de valores se altera em prol da nova prioridade, que é a droga, começando inclusivamente a adotar comportamentos desviantes. Posto isto, consideramos que seria relevante, como sugestão de um estudo futuro (possivelmente de cariz quantitativo), conhecer em profundidade a estrutura de valores do sujeito adicto e averiguar, não só de que forma esses valores relacionam-se com os consumos, como explorar de que forma sustentam/justificam o desenvolvimento de comportamentos desviantes (nomeadamente o surgimento da delinquência e do crime).

\section{Conclusão}

A presente investigação pretendeu analisar a dependência de droga, com base na perspectiva de quem a vivenciou. Nesse sentido, sublinha-se a importância da metodologia TFD como instrumento de investigação, já que foi por meio desta que o acesso em profundidade às narrativas pessoais dos sujeitos foi possível.

Verificou-se diversidade de fonte, e a quantidade e qualidade dos dados revelaram-se consistentes e suficientes para responder às questões de investigação. Assim, relativamente à questão sobre o que leva o sujeito a consumir, a investigação revelou que dois dos utentes relacionaram os primeiros consumos com momentos de vida particularmente difíceis, referindo que utilizaram a droga como uma forma de "apagar" as emoções negativas. No entanto, os demais sujeitos não estabelecem qualquer relação entre os primeiros consumos e situações de vida particulares, explicando que entraram no mundo das drogas por curiosidade. Com relação à forma como se desenrola a trajetória dependente, verificou-se que a droga vai assumindo um lugar central na vida dos consumidores, levando o seu sentido de vida a afunilar.

A investigação revelou que ao longo dessas trajetórias, os sujeitos vão atribuindo diferentes significados à droga e ao sentido das suas vidas; no entanto, foi unânime a identificação de um sentimento profundo de mudanças de identidade, fortemente associadas a uma alteração de valores morais e sociais. Os sujeitos olham atualmente para a droga com sentimentos profundos de culpa e arrependimento, referindo-se a ela como a sua autodestruição.

Tendo em conta a categoria nuclear encontrada, esta investigação revelou a presença de uma identidade frágil e imatura no sujeito dependente. Assim, acredita-se que nas adições, para além do tratamento médico e sintomático, é fundamental a intervenção psicológica, com enfoque nos aspetos da re(construção) da identidade.

Esta questão torna-se ainda mais relevante, tendo em vista que a maioria dos sujeitos inicia 
o percurso nas drogas durante a adolescência, fase crucial de autoconhecimento, maturação e consolidação do self. Crescendo sob o consumo de drogas, o adulto adicto acaba por não se conhecer verdadeiramente na ausência do uso de substâncias.

Assim, considera-se que o tratamento da dependência deverá constituir-se como um espaço integrador das diversas vivências de adição e proporcionar ao utente um percurso de autoconhecimento, visando à superação das fragilidades de identidade e o alcance de um sentimento de si, íntegro, coeso e sólido.

\section{Colaborações}

1 - concepção, projeto, análise e interpretação dos dados: Mariana Morais e Rui Paixão;

2 - redação do artigo e revisão crítica relevante do conteúdo intelectual: Mariana Morais;

3 - aprovação final da versão a ser publicada: Rui Paixão.

\section{Referências}

1. Gomes-Medeiros D, Faria P, Campos GWS, Tófoli LF. Política de drogas e Saúde Coletiva: diálogos necessários. Cad Saúde Pública. 2019;35(7):e00242618. DOI:10.1590/0102$311 \times 00242618$

2. Organização Mundial de Saúde. Global status report on alcohol and health 2018 [Internet]. Geneva (CH); 2018 [cited 2020 Mar 12]. Available from: https://apps.who.int/iris/bitstream/handle/ 10665/274603/9789241565639-eng.pdf?ua=1

3. Maciel M. Assistência de enfermagem prestada aos usuários de drogas ilícitas: revisão de literatura. Rev Saúde Desenvol [Internet]. 2017 [cited 2020 Mar 12];11(7):10-22. Available from: https:// www.uninter.com/revistasaude/index.php/ saudeDesenvolvimento/article/view/591/391

4. Ralph N, Birks M, Chapman Y. The methodological dynamism of grounded theory. Int J Qual Methods. 2015; 14(4):1-6. DOI: https//doi. org. $10.1177 / 1609406915611576$

5. Redman-Maclaren M, Mills J. Transformational grounded theory: theory, voice and action.
Int J Qual Methods. 2015;14(3):1-12. DOI: $10.1177 / 160940691501400301$

6. Corbin J, Strauss A. Basics of qualitative research: Techniques and procedures for developing grounded theory. 3rd ed. Thousand Oaks (CA): Sage Publications; 2008.

7. Almeida L. Metodologia da investigação em psicologia e educação. 5a ed. Braga (PT): Psiquilibrios; 2008.

8. Silverman D. Doing qualitative research. 4th ed. London (GB): Sage Publications; 2013.

9. Charmaz K. Constructing grounded theory. 2nd ed. London (GB): Sage Publications; 2014.

10. Strauss A, Corbin J. Basics of qualitative research. 2nd ed. Thousand Oaks (CA): Sage Publications; 1998.

11. Lima LN, Ferro MJ. Grounded theory: Uma Metodologia Qualitativa de Investigação. Manual Pedagógico de Apoio ao Seminário de Investigação da Faculdade de Psicologia e Ciências da Educação da Universidade de Coimbra. Coimbra (PT): Faculdade de Psicologia e Ciências da Educação da Universidade de Coimbra; 2014.

12. Erikson E. Identidade, juventude e crise. Rio de Janeiro: Zahar; 1976.

13. Grinberg L, Grinberg R. Identidade e mudança. Lisboa (PT): Climepsi; 1976.

14. Dias F. Educação e projeto de vida. Antes e depois da toxicodependência. Lisboa (PT): Instituto Piaget; 2003.

15. Correia V. Parentalidade e toxicodependência: o caso da paternidade [tese]. Porto (PT): Universidade Católica Portuguesa; 2015.

16. Patrício LD. Droga para que se saiba. Lisboa (PT): Figueirinhas; 2002.

17. Rodrigues V. A relação entre família, toxicodependência e crime: um estudo na população ex-reclusa [tese]. Lisboa (PT): Universidade Autónoma de Lisboa; 2018.

18. Dias DRS. Comportamento delinquente e consumo de substâncias psicoativas ilícitas em jovens com inquérito/medida tutelar educativa [tese]. Porto (PT): Universidade Católica Portuguesa; 2015.

19. Rafaiee R, Olyaee S, Sargolzaiee A. The relationship between the type of crime and drugs in addicted prisoners in Zahedan Central Prison. Int J High Risk Behav Addict. 2013;2(3):139-40. DOI: 10.5812/ijhrba.13977 
20. Keating JP. Psicoterapia individual em comunidade terapêutica para toxicodependentes: clivagem, difusão de identidade e integração. Rev Toxicodependências [Internet]. 2011 [cited 2020 Mar 12];17(3):3-11. Available from: http:// www.sicad.pt/BK/RevistaToxicodependencias/ Lists/SICAD_Artigos/Attachments/542/artigo1_ Toxico3_2011.pdf

21. Fabião C. Toxicodependência: duplo diagnóstico, alexitimia e comportamento. Uma revisão [Internet]. Rev Toxicodependências. 2002 [cited 2020 Mar 12];8(2):37-49. Available from: http://www.sicad. pt/BK/RevistaToxicodependencias/Lists/SICAD_ Artigos/Attachments/285/2002_02_TXT5.pdf

22. Mendes JAR. Vivência familiar e personalidade em toxicodependentes [tese]. Coimbra (PT): Faculdade de Medicina da Universidade de Coimbra; 2015.
23. Observatório Europeu da Droga e da Toxicodependência. Relatório Europeu sobre Drogas 2016: tendências e evoluções. Luxemburgo: Serviço das Publicações da União Europeia; 2016.

24. Santos JCC. Comorbilidade na toxicodependência e motivação para o tratamento [tese]. Faro (PT): Universidade do Algarve; 2016.

25. Chora SHJL. Atitudes face à droga de toxicodependentes: medidas implícitas e explícitas e regulação emocional. Portugal [tese]. Lisboa (PT): Instituto Universitário de Ciências Psicológicas, Sociais e da Vida; 2014.

Recebido: 28 de dezembro de 2019

Aprovado: 2 de março de 2020

Publicado: 29 de abril de 2020

A Revista Baiana de Enfermagem utiliza a Licença Creative Commons - Atribuição-NãoComercial 4.0 Internacional.

https://creativecommons.org/licenses/by-nc/4.0/

Este artigo é de acesso aberto distribuído sob os termos da Licença Creative Commons (CC BY-NC).

Esta licença permite que outros remixem, adaptem e criem a partir do seu trabalho para fins não comerciais.

Embora os novos trabalhos tenham de lhe atribuir o devido crédito e não possam ser usados para fins comerciais, os usuários não têm de licenciar esses trabalhos derivados sob os mesmos termos. 